\title{
PRODUCTION OF COPPER POWDER FROM PRINTED CIRCUIT BOARDS BY ELECTRODEPOSITION
}

\author{
I. MASAVETAS ${ }^{1}$ \\ A. MOUTSATSOU ${ }^{1, *}$ \\ E. NIKOLAOU ${ }^{1}$ \\ S. SPANOU ${ }^{2}$ \\ A. ZOIKIS-KARATHANASIS ${ }^{2}$ \\ E.A. PAVLATOU ${ }^{2}$ \\ N. SPYRELLIS ${ }^{2 \dagger}$
}

Received: 30/09/08

Accepted: 29/01/09

\author{
${ }^{1}$ Laboratory of Inorganic and Analytical Chemistry \\ ${ }^{2}$ General Chemistry Laboratory \\ School of Chemical Engineering, \\ National Technical University of Athens \\ 9, Iroon Polytechneinou str., Polytechnioupolis \\ 157 73, Zografou, Athens, Greece
}

*to whom all correspondence should be addressed: e-mail: angst@central.ntua.gr

\begin{abstract}
During the last years, the waste electrical and electronic equipment (WEEE) are gathering attention, as a very special section of waste. In fact, they have been proven to be source for the recovery of metals. In the present study printed circuit boards (PCBs) were cut and treated thermally at $500^{\circ} \mathrm{C}$ for $1 \mathrm{~h}$ in both air and nitrogen atmosphere. The obtained material was dissolved in three different acid media $\mathrm{HNO}_{3 a q}, \mathrm{HCl}_{\text {aq }}$ and $\mathrm{H}_{2} \mathrm{SO}_{4 \mathrm{aq}}$, in order to extract copper. The achieved $\mathrm{Cu}$ recovery percentages were $97.5,65$ and $76.5 \%$ respectively. Electrodeposition technique was applied in order to recover copper in powder form. More than $98 \%$ of copper was recovered achieved by application of high current density resulting to dendritic structure of copper. The applied process was characterised by a high current efficiency and led to the production of copper powder of $80 \mu \mathrm{m}$ mean diameter appropriate for powder metallurgy applications.
\end{abstract}

KEYWORDS: Printed circuit boards, leaching, electrowinning, Cu recovery, Cu powder.

\section{INTRODUCTION}

Due to the rapid technological progress, the replacement of electronic equipment is very often necessary, leading to huge amounts that end up as waste. In addition, waste electrical and electronic equipment (WEEE) contains metals of high commercial value and others that are supposed to be hazardous for the environment. Consequently, WEEE could be considered as a significant source for recovery of non-ferrous metals. Among these waste, computers appear to be distinctive, as far as further exploitation is concerned. According to studies carried out, computers seem to be the only WEEE that could allow a system to be financially beneficial (PriceWaterHouseCoopers, 2002). The most "useful" parts of the computers are the printed circuit boards (PCBs) that contain many metals of interest. A typical weight distribution indicates that PCBs represent approximately $13 \%$ of the weight of a desktop personal computer unit (Menegaki et al., 2006). Statistics reveal that the amount of WEEE produced per year in Europe is approximately $6.000 .000 \mathrm{tn}$, with a growing rate of $3-5 \%$ per year (Kirkitsos et al., 2002). In Greece, for the year 2007, the household WEEE produced is estimated to be 100.000 tn (Polychronopoulou et al., 2006). Moreover, by taking into consideration the so-called "historic waste" (waste that their owners, for various reasons, are unwilling to discard), one comes up with a sum that would have fatal consequences if these waste reach the current land-filling system.

The methods that can be used in order to recover metals from computers are basically the physical/mechanical and the chemical separation. In Greece, during the last years the first steps have been attempted, concerning mainly the physical/mechanical separation. As far as concerning chemical separation, electrowinning, hydrometallurgy and pyrometallurgy are 
widely utilized. Electrowinning has the potent advantages of not producing considerable amounts of by-products that have negative environmental impact, as opposed to both other methods and resulting in products of high purity (Veit et al., 2006). In the last decade, several studies have been reported in the literature, concerning the feasibility of copper recovery from (WEEE) leaching solutions by electrodeposition technique (Mecucci and Scott, 2002; Pilone and Kelsall, 2006; Veit et al., 2006; Oishi et al., 2007). In addition, patents concerning aqueous leaching and electrowinning have been developed for recycling metals ( $\mathrm{Au}, \mathrm{Ag}, \mathrm{Cu}$, $\mathrm{Pd}, \mathrm{Pb}, \mathrm{Sn}$ ) from the increasing volumes of WEEE (Brandon et al., 2002). It is noteworthy that, as mentioned above, although there is a growing up research work concerning either the proper selection of the leaching solution (alkaline or acidic) or the effectiveness of copper recovery, no attention has been paid on the relationship between the applied electrolytic conditions and the recovered copper structure, up to the authors' knowledge.

In the present work, electrowinning is to be considered since it is applied to the primary metallurgy of copper, which is the target metal for recovery from PCBs waste. Specifically, a combination of copper leaching and electrodeposition was applied in order to produce copper powder, appropriate for powder metallurgical applications. PCBs were treated with $\mathrm{HNO}_{3 \mathrm{aq}}$, $\mathrm{HCl}_{\mathrm{aq}}$ and $\mathrm{H}_{2} \mathrm{SO}_{4 \mathrm{aq}}$ and the resultant solutions were subjected to electrolysis by appropriate control of the cathodic potential in order to achieve selective deposition of copper and thus, leading to the recovery of high purity copper powder.

\section{EXPERIMENTAL}

Printed circuit boards (PCBs) from personal computers were used as a raw material. Firstly, the PCBs were mechanically cut into smaller pieces of about $1 \times 2 \mathrm{~cm}$. Afterwards a thermal pretreatment was carried out for the separation of the non metallic parts. The PCB pieces were heated into an electrical furnace at $500{ }^{\circ} \mathrm{C}$ for a period of $1 \mathrm{~h}$. This procedure was carried out in both air and nitrogen atmosphere, so as to investigate the impact that this may have on the obtained samples. During the heating, a loss on ignition of approximately $22 \%$ took place. Thermal investigation of the treated samples, by Thermogravimetric Analysis (TG) (Mettler Toledo TGA/SDTA851 ${ }^{\mathrm{e}}$ ) showed that the treating time was efficient, since no significant further loss of mass was traced. This process was very important for the further treatment, since it removed the non metallic parts of the samples, resulting in a more effective dissolution. The treated samples were ground in a lab-mill apparatus (FRITSCH pulverisette 2) for $5 \mathrm{~min}$, which led to powder samples, entirely passing the $90 \mu \mathrm{m}$ sieve. The composition of the obtained powder samples, as determined by X-ray fluorescence (XRF) (THERMO A.R.L. ADVANT'XP), is presented in table 1.

Table 1. Composition of the obtained PCB powder after mechanical and thermal treatment

\begin{tabular}{cc||cc}
\hline Elements & Content (\%) & Elements & Content (\%) \\
\hline $\mathrm{Si}$ & 39.5 & $\mathrm{Fe}$ & 0.7 \\
$\mathrm{Ca}$ & 20.8 & $\mathrm{Mg}$ & 0.6 \\
$\mathrm{Cu}$ & 17.0 & $\mathrm{Ti}$ & 0.5 \\
$\mathrm{Al}$ & 7.5 & $\mathrm{Sb}$ & 0.3 \\
$\mathrm{~Pb}$ & 4.1 & $\mathrm{Ag}$ & $930 \mathrm{ppm}$ \\
$\mathrm{Sn}$ & 3.1 & $\mathrm{Zr}$ & $160 \mathrm{ppm}$ \\
$\mathrm{Zn}$ & 1.1 & $\mathrm{Cr}$ & $130 \mathrm{ppm}$ \\
$\mathrm{Ni}$ & 0.9 & $\mathrm{Mn}$ & $120 \mathrm{ppm}$ \\
\hline
\end{tabular}

Powder samples were examined by X-ray diffraction (XRD) (Siemens D5000 Diffractometer, $\mathrm{Cu} \mathrm{Ka}$ radiation, Ni Filter), indicated that the samples contained a considerable amount of quartz mainly produced during the combustion, as well as $\mathrm{Cu}, \mathrm{CuO}$ (tenorite), $\mathrm{Zn}, \mathrm{ZnO}, \mathrm{NiO}$, $\mathrm{Pb}$ and $\mathrm{SnO}_{2}$ (cassiterite) (Moutsatsou et. al., 2007). No significant difference in the presence of oxides was traced at the samples that were heated in nitrogen atmosphere. Chemical analysis of compounds resulted in concentration of $\mathrm{Cu}$ of approximately $17 \% \mathrm{w} / \mathrm{w}$. It should be taken into consideration, though, that PCBs' concentration in metals can vary, depending on the parts that are subjected to examination. 
Proceeding to the main part of the experimental work, baths were used for the leaching of metals. The solvents used were $\mathrm{HCl}_{a q}, \mathrm{H}_{2} \mathrm{SO}_{4 a q}$, as the most commonly used solvents, due to their lower cost, although $\mathrm{H}_{2} \mathrm{SO}_{4 a q}$ may lead to sulphur content in powder interfering properties, as well as $\mathrm{HNO}_{3 \text { aq }}$ of analytical grade. The latter demonstrates the higher leaching efficiency of metals and is the proper acid bath for electrodeposition. The PCB samples were treated with concentrated acids, at a temperature range of $40-80^{\circ} \mathrm{C}$. According to a series of experiments that were carried out, the optimum temperature for the leaching proved to be 80 ${ }^{\circ} \mathrm{C}$. Stirring was applied during each test, to improve the leaching efficiency (Vegliò et al., 2003) and then the solutions were diluted to achieve concentrations of about $2 \mathrm{M}$, appropriate for the electrowinning.

Cyclic linear sweep voltammetry was employed to obtain information on current potential behavior of metals in the three leaching solutions. Actually, as the solutions contain a variety of chemical species, the purpose was to define the area where the reduction of copper takes place as well as, to determine other simultaneous reactions that could occur at the cathode. The electrodeposition took place at a three electrode electrolytic cell of 0.5 I volume. The potential was set at $-250 \mathrm{mV}$ vs SCE in order to allow the selective deposition of copper. A $2.5 \mathrm{~cm}^{2}$ copper plate of $99.9 \%$ purity was used as cathode, which prior to electrodeposition was etched in $0,5 \mathrm{M} \mathrm{H}_{2} \mathrm{SO}_{4}$ solution, and a platinum grid was employed as anode. The applied current during the electrowinning was at $\sim 2.3 \mathrm{~A}$, so as a dendritic structure to be obtained (Fleury and Barkley, 1996). The scheme of the electrolytic cell is depicted in Figure 1.

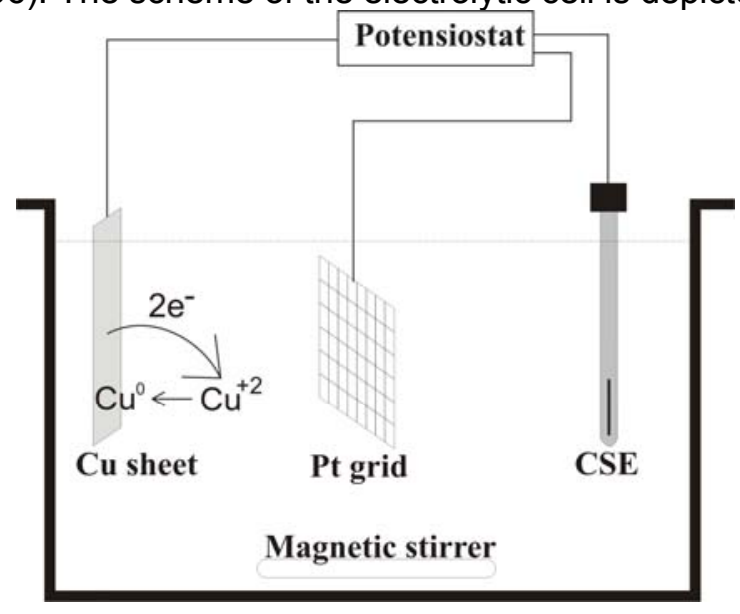

Figure 1. Schematic representation of the electrolytic cell

All electrodepositions were carried out at room temperature. The concentration of $\mathrm{Cu}$ in the solution before and after the electrodeposition was determined by using Atomic Absorption Sprectroscopy (AAS) (Perkin Elmer 3300).

The composition of the recovered metal was determined by energy dispersive X-ray spectroscopy (EDS), while the structure was examined by using XRD. Moreover, the morphology of the recovered copper was observed by scanning electron microscopy (SEM) (FEI QUANTA 200). Finally, the grain size distribution of produced copper powder was examined by Laser Particle size analysis (Malvern Mastersizer Micro).

\section{RESULTS AND DISCUSSION}

Concerning the leaching behavior of metals, the concentration of $\mathrm{Cu}$ at the obtained samples was determined by Flame Atomic Absorption Spectrometry. The percentage of recovery was calculated by comparing the leached concentration to the concentration that resulted from the complete dissolution with aqua regia. The achieved $\mathrm{Cu}$ recovery was $97.5 \%$ for $\mathrm{HNO}_{3 a q}, 65 \%$ for $\mathrm{HCl}_{\mathrm{aq}}$ and $76.5 \%$ for $\mathrm{H}_{2} \mathrm{SO}_{4 \mathrm{aq}}$, respectively. Thus, the concentration of copper in the solutions was 3.32, 2.2 and $2.6 \mathrm{~g} \mathrm{I}^{-1}$ for the $\mathrm{HNO}_{3 \mathrm{aq}}, \mathrm{HCl}_{\mathrm{aq}}$ and $\mathrm{H}_{2} \mathrm{SO}_{4 \mathrm{aq}}$, correspondingly.

Due to the composition of the obtained solutions after leaching, a possible shift in the standard reaction potential of copper could be observed as well as, other parallel reactions on the cathode might occur during the electrodeposition (Pilone and Kelsall, 2006). Figure 2 demonstrates the cyclic voltammetry $(\mathrm{CV})$ diagrams in the three leaching solutions obtained 
with initial and final potential of +300 and $-300 \mathrm{mV} / \mathrm{SCE}$, respectively. It is apparent that the reduction of copper started at $+90,+40$ and $0 \mathrm{mV}$ in the case of sulphuric, nitric and hydrochloric acid, respectively (eq. 1). Regarding nitric acid solution, a cathodic reduction of hydrogen (eq. 2) took place at $-280 \mathrm{mV}$ while no other reactions were detected apart from copper deposition. Concerning the leaching solution of hydrochloric acid, an inhibitive action took place at $-180 \mathrm{mV}$ leading to a decrease of current. In detail, at this voltage the reduction of $\mathrm{Cu}^{+2}$ to $\mathrm{Cu}^{+1}$ (eq. 3) is favoured (Bard and Faulkner, 1983) and as a result a local increase of $\mathrm{Cu}^{+1}$ concentration is provoked, which consequently leads to the formation of $\mathrm{CuCl}$, resulting in partial passivation of the cathode and finally to current decrement (Figure 2). On the other hand, sulphuric acid solution demonstrated a rather steady cathodic current behaviour, probably due to the diffusion transfer control of $\mathrm{Cu}^{+2}$. In both cases of hydrochloric and sulphuric acid solutions the hydrogen evolution reaction was shifted to more negative potential values.

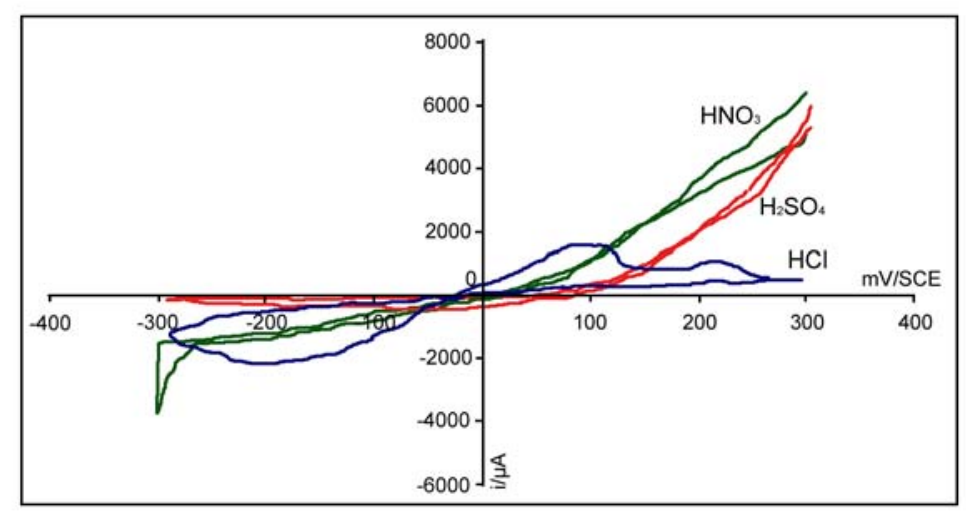

Figure 2. Cyclic voltammograms obtained from the three leaching solutions in the region of $+300 /-300 \mathrm{mV}$, and scan rate: $5 \mathrm{~m} \mathrm{~V}^{-1}$

$\mathrm{Cu}^{+2}+2 \mathrm{e}^{-} \rightarrow \mathrm{Cu}^{0}$

$2 \mathrm{H}^{+}+2 \mathrm{e}^{-} \rightarrow \mathrm{H}_{2}$

$\mathrm{Cu}^{+2}+\mathrm{e}^{-} \rightarrow \mathrm{Cu}^{+1}$

AAS measurements of metals concentration were performed to ascertain that no other metals, apart from copper, have been deposited. The recovery percentage of copper is presented in Figure 3 and it is clear that in all cases more than $98 \%$ was obtained. Furthermore, current efficiency was calculated by applying Faraday's law (Figure 3).

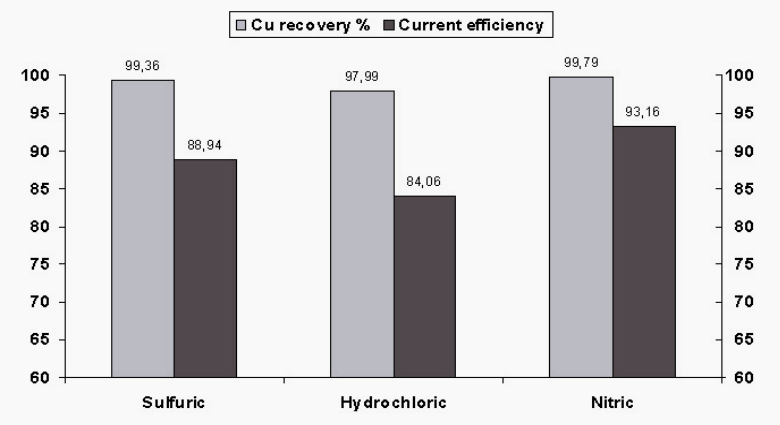

Figure 3. Copper recovery percentage and current efficiency of electrolysis for the three leaching solutions

It is worth mentioning that current efficiencies for all leaching solutions were high indicating a restriction of the simultaneous hydrogen evolution, although the $\mathrm{pH}$ of all electrolytic solutions was significantly lower than that used in normal copper electrodeposition (Vicenzo and 
Cavallotti, 2002). The results of AAS measurements regarding other metals $\left(\mathrm{Pb}^{+2}, \mathrm{Ni}^{+2}\right.$ ect.) revealed negligible alteration of their concentration in the bath after electrodeposition proving that only copper was deposited on the cathode.

Concerning the morphology of the recovered copper, SEM images revealed dendritic growth of the deposits obtained from all three leaching solutions (Figures $4,6 b$ ). Specifically, in the case of the copper obtained from the sulphuric acid solution the recovered metal presented fine dendritic structure with branches of about $80-100 \mu m$ (Figure 4a). On the other hand, copper deposited from nitric or hydrochloric acid solutions demonstrated a more compact structure although a dendritic structure was conserved. It should be noticed that this type of structure is appropriate for powder metallurgy applications and was achieved by applying high current density $\left(30 \mathrm{~A} \mathrm{dm}^{-2}\right)$ during electolysis. Laser particle size analysis at the obtained copper powders regardless the leaching solution indicated that the mean diameter was about $80 \mu \mathrm{m}$ verifying the fine dendrite structure. It should be mentioned that after electrodeposition no further grinding process is needed in order to receive fine powder.
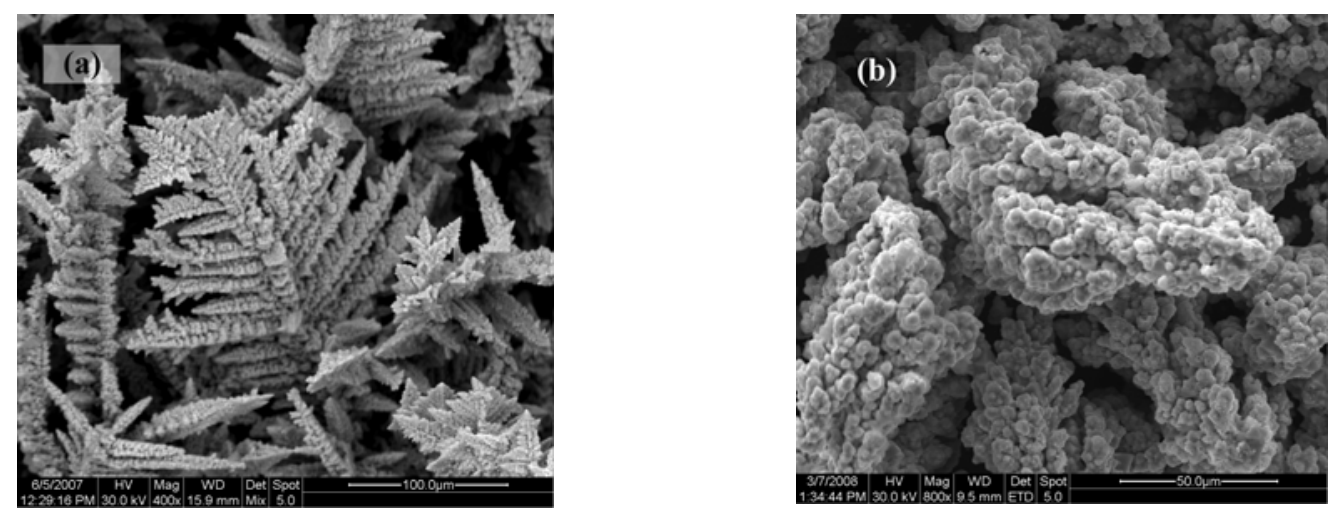

Figure 4. SEM images of recovered copper revealing the dendritic morphology from (a) $\mathrm{H}_{2} \mathrm{SO}_{4}$ solution and (b) $\mathrm{HNO}_{3}$ solution

In the case of copper recovered from sulphuric and nitric acid leaching solutions, EDX analysis on the deposits showed copper with a significant amount of oxygen, while no other metals were detected. XRD analysis on the corresponding deposits demonstrated the presence of $\mathrm{Cu}$ as well as of $\mathrm{Cu}_{2} \mathrm{O}$ (Figure 5). The oxide was mainly observed in the case of copper recovered from nitric acid solution (Figure 5). Consequently, the presence of oxygen detected in EDX analysis could be attributed to $\mathrm{Cu}_{2} \mathrm{O}$, which probably originates from surface oxidation of copper, as it is known that electrodeposition of $\mathrm{Cu}_{2} \mathrm{O}$ takes place only in alkaline solutions (Jongh et al., 1999). In the case of copper deposits obtained from hydrochloric acid solutions, EDX analysis revealed the existence of lead and chlorine (Figure 6a). Furthermore, diffraction peaks of $\mathrm{PbCl}_{2}$ were detected in XRD diagrams (Figure 5). Detailed analysis using SEM and EDX spot analysis showed that $\mathrm{PbCl}_{2}$ precipitate was co-deposited on the cathode (Figure 6b). The presence of $\mathrm{PbCl}_{2}$ in the deposited metal could be attributed to the local increase of $\mathrm{Pb}^{+2}$ concentration in the catholyte area resulting to the precipitation of $\mathrm{PbCl}_{2} . \mathrm{A}$ similar phenomenon could be accomplished in the case of sulphuric acid solutions, but $\mathrm{PbSO}_{4}$ was not detected probably due to minor mobility of $\mathrm{SO}_{4}^{-2}$ anions towards the cathode. 


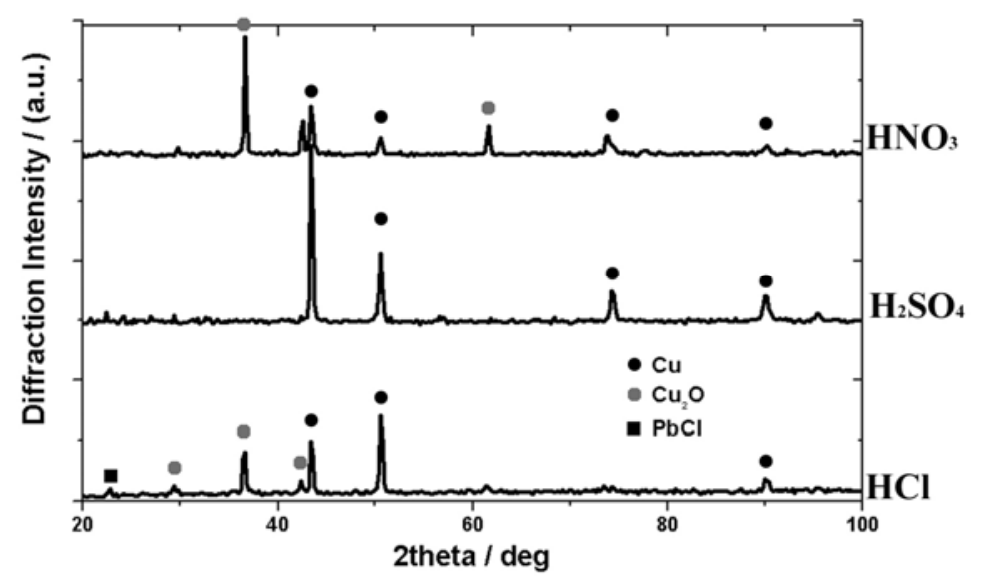

Figure 5. X-ray Diffraction diagrams of the recovered copper from the $\mathrm{HCl}, \mathrm{H}_{2} \mathrm{SO}_{4}$ and $\mathrm{HNO}_{3}$ leaching solutions

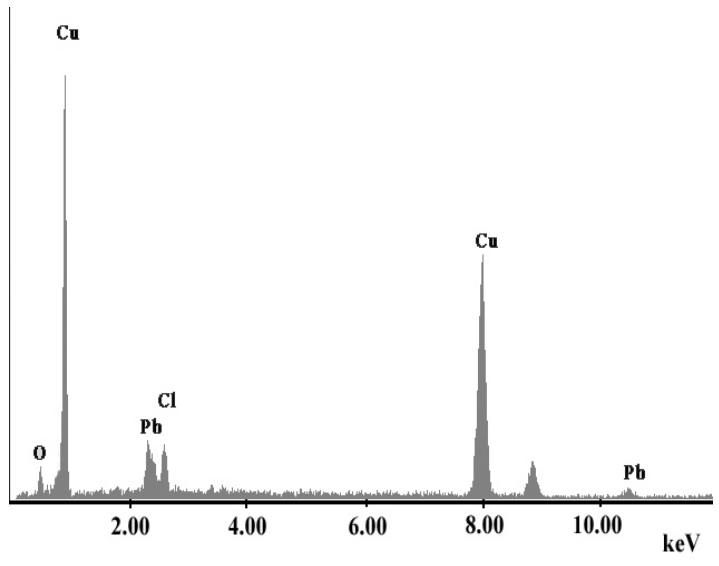

Figure 6a. EDX analysis of copper deposit from $\mathrm{HCl}$ acid solution.

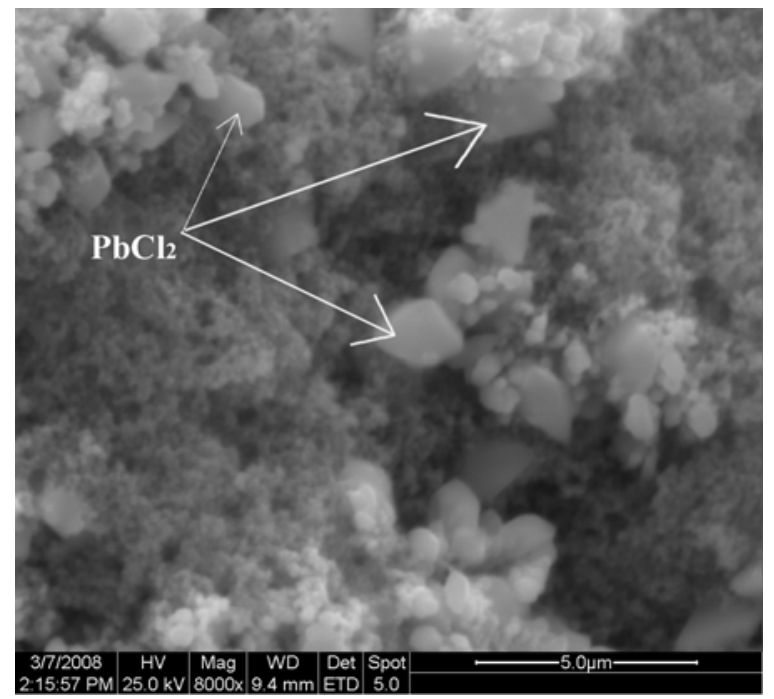

Figure $6 b$. SEM image of copper deposit from $\mathrm{HCl}$ acid solution where the $\mathrm{PbCl}_{2}$ particles are obvious

\section{CONCLUSIONS}

WEEE and especially PCBs can prove to be a very promising resource for the recovery of metals of high commercial value. This is attributed to their considerable amount ending up as waste, as well as their high value metal composition. The current research led to the following results.

$\checkmark$ In order to achieve the recovery of copper from PCBs, it should be taken into consideration that a pre-treatment process is necessary, so as to obtain samples suitable for leaching of metals.

$\checkmark$ All three leaching solutions $\left(\mathrm{HNO}_{3 \mathrm{aq}}, \mathrm{HCl}_{\mathrm{aq}}\right.$ and $\left.\mathrm{H}_{2} \mathrm{SO}_{4 \mathrm{aq}}\right)$ exhibited adequate solubility behaviour for copper.

$\checkmark$ The application of electrodeposition as a technique for the recovery of $\mathrm{Cu}$ from acid leaching solutions resulted in high percentage of copper recovery since more than $98 \%$ of copper was obtained.

$\checkmark$ Under specific electrolytic experimental conditions copper can be recovered in a suitable structure, from which fine powder can be easily produced. 


\section{REFERENCES}

Bard A. and Faulkner L., (1983), Électrochime, Principles, methods et applications, Masson, Paris Brandon N.P., Kelsall G.H., Yin Q., Electrolytic extraction of metals, recycling, 2002, UK Patent Application 2368 349, 1.5.

Fleury V. and Barkey D., (1996), Branched copper electrodeposition on a substrate, Physica A, 233, 730-741.

Jongh P.E., Vanmaekelbergh D. and Kelly J.J., (1999), $\mathrm{Cu}_{2} \mathrm{O}$ : Electrodeposition and characterization, Chem. Mater., 11, 3512-3517.

Kirkitsos Ph., Chrisogelos N. and Dalamanga A., (2002), Sustainable management of e-waste in Greece, Final report of LIFE00 ENV/GR/000688, Athens.

Mecucci A. and Scott K., (2002), Leaching and electrochemical recovery of copper, lead and tin from scrap printed circuit boards, J. Chem. Technol. Biotechnol., 77, 449-457.

Menegaki M.E., Karachaliou T.I. and. Kaliampakos D.C, (2006), Critical parameters for the design of an e-waste management system in Greece, Proceedings of the 8th Conference for the Protection And Restoration of the Environment, Chania, Greece (in CDrom).

Moutsatsou A, Georgakopoulos L and Masavetas I., (2007), Waste Electrical and Electronic Equipment's Behaviour in Acid Media, Proceedings of Bio- Hydrometallurgy, Falmouth, UK, (in CDrom).

Oishi T., Koyama K., Alam S., Tanaka M. and Lee J.-C., (2007), Recovery of high purity copper cathode from printed circuit boards using ammoniacal sulfate or chloride solutions, Hydrometallurgy, 89, 82-88.

Pilone D. and Kelsall G.H., (2006), Prediction and measurement of multi-metal electrodeposition rates and efficiencies in aqueous acidic chloride media, Electrochimica Acta, 51, 3802-3808

Polychronopoulou H., Chalarakis E. and Bourka A., (2006), WEEE production in GreeceTechnological synopsis of WEEE treatment methods, Proceedings of the 2nd international conference of HSWMA, Athens, Greece, (in CDrom).

PricewarehouseCoopers, (2002), Environmental life cycle assessment and financial life cycle analysis of the WEEE directive and its implications for the UK, Final report, 30-33.

Vegliò F., Quaresima R., Fornari P. and Ubaldini S., (2003), Recovery of valuable metals from electronic and galvanic industrial wastes by leaching and electrowinning, , Waste Management, 23, 245-252.

Veit H.M., Bernades A.M., Ferreira J.Z., Tenorio J.A.S. and Malfatti C.F., (2006), Recovery of copper from printed circuit boards scraps by mechanical processing and electrometallurgy, $\mathrm{J}$. Hazard. Mater., B137, 1704-1709.

Vicenzo A. and Cavallotti P.L., (2002), Copper electrodeposition from a pH 3 sulfate electrolyte, J. Appl. Electrochem., 32, 743-753. 